\title{
Does image file transfer, exposure time and optimization algorithm affect digital intraoral radiographs?
}

\author{
Wojciech Grzebieluch ${ }^{1, A-D}$, Urszula Kaczmarek ${ }^{2, D-F}$, Tomasz Staniowski, ${ }^{2, B-D}$, Marcin Mikulewicz ${ }^{3, D-F}$ \\ ${ }^{1}$ Laboratory for Digital Dentistry, Department of Conservative Dentistry and Pedodontics, Wroclaw Medical University, Poland \\ 2 Department of Conservative Dentistry and Pedodontics, Wroclaw Medical University, Poland \\ ${ }^{3}$ Division of Facial Abnormalities, Department of Maxillofacial Orthopedics and Orthodontics, Wroclaw Medical University, Poland \\ A - research concept and design; B - collection and/or assembly of data; C - data analysis and interpretation; \\ $\mathrm{D}$ - writing the article; $\mathrm{E}$ - critical revision of the article; $\mathrm{F}$ - final approval of the article
}

Address for correspondence

Wojciech Grzebieluch

E-mail:dentysta@poczta.fm

Funding sources

None declared

Conflict of interest

None declared

Received on July 21,2020

Reviewed on July 24, 2020

Accepted on 0ctober 8, 2020
Cite as

Grzebieluch W, Kaczmarek U, Staniowski T, Mikulewicz M.

Does image file transfer, exposure time and optimization algorithm affect digital intraoral radiographs? Adv Clin Exp Med. 2020;29(12):1449-1458. doi:10.17219/acem/128231

DOI

10.17219/acem/128231

Copyright

Copyright by Author(s)

This is an article distributed under the terms of the

Creative Commons Attribution 3.0 Unported (CC BY 3.0)

(https://creativecommons.org/licenses/by/3.0/)

\begin{abstract}
Background. The transfer of digital radiographic images is widely practiced. Digital image processing can influence the perception of image quality. The question arises as to how exposure, internal image adjusting algorithms and image file transfer affect the optical density of digital radiographs.

Objectives. To evaluate the influence of exposure time, optimization and file transfer on digital radiographs.

Material and methods. Calibration patterns were formed and a series of digital radiograms were recorded under standardized conditions. The radiographs were exported and then imported into the same software. Three groups of radiographs were analyzed: $A$ - images originally performed and recorded in the software; $B$-images imported after exporting an optimized image; and C - images imported after exporting an image without optimization but with measurements of the density of the marked regions of interest.
\end{abstract}

Results. An increase of the exposure time decreases optical density. The optimization algorithm increases contrast and decreases differences between exposure times. Long exposures affect the visibility of objects with low optical density. After importing the images in Group B, there was a risk of using the optimization algorithm twice. When optimization was not performed, there were no differences between Groups B and A. In Group C, there was no risk of doubling the optimization algorithm.

Conclusions. The transfer of digital radiographs can exert an influence on the optical density values. To avoid the risk of image distortion, files should be exported without image optimization.

Key words: image analysis, digital radiography, image transfer 


\section{Introduction}

The traditional technology using X-ray films is being replaced by digital radiography and other digital technologies. Images recorded on radiographs are black and white and individual pixels possess a specific lightness ranging from 0 to 255 (256-grade 8-bit grayscale - the scale of optical density). The brighter the area appears on radiographs, the higher the optical density. The software (the internal algorithms of image processing) compensates for changes in exposure time and allows the images to have suitable brightness and contrast; therefore, "lighted" (dark) or "under-exposed" (bright) images are uncommon. ${ }^{1,2}$ Digital processing of image parameters such as brightness, contrast, sharpening, smoothing, and zooming can correct the visibility of certain regions, making the image more accessible to the human eye. However, digital image processing can produce artefacts that may resemble pathologies. ${ }^{3-5}$ The software also makes it possible to measure the length, angle and optical density of selected areas of the image. ${ }^{6,7}$ In the case of measuring the length of an object, the picture can be calibrated; however, in case of the optical density measurements (radiodensitometry and radioabsorption), this is not possible. The transfer of digital radiographs and the scanning of conventional radiographs to obtain a digital image is practiced widely, but digital processing of an image can have some impact on both the diagnostic value of the X-ray image and the subjective perception of the image quality. ${ }^{8}$

The advantage of digital images lies in the ease of storage and transferring. However, it should be also remembered that most dental software uses an internal, integrated optimization algorithm to compensate for the exposure conditions and sensor properties. Therefore, the question arises as to how the exposure conditions, internal image adjusting algorithms and image file transfer affect the optical density of digital radiographs. There is a lack of data in the available literature on this topic.

The purpose of the study was to evaluate the impact that file transfer, exposure time and the optimization algorithm have on the optical density of dental radiographs.

\section{Material and methods}

A pattern containing 2 separate stepped-wedge patterns for digital radiographs was produced. Pattern 1 was formed from aluminum and consisted of 5 steps: $0.7 \mathrm{~mm}, 1.3 \mathrm{~mm}$, $1.9 \mathrm{~mm}, 2.5 \mathrm{~mm}$, and $3.1 \mathrm{~mm}$. Pattern 2, showing lower radiolucency, was made from lead foil that originated from radiographic film (Foton Dental DX-D 3-4 cm ANSI 1. ISO W2 Emulsion No. 00905.3; Foton, Warsaw, Poland) and consisted of 4 steps formed by 1-4 foil layers (Fig. 1). Radiographs were taken with a digital radiography Dixi 3-CCD sensor (Planmeca, Helsinki, Finland), Planmeca Intra X-ray apparatus (Planmeca) and Dimaxis Classic

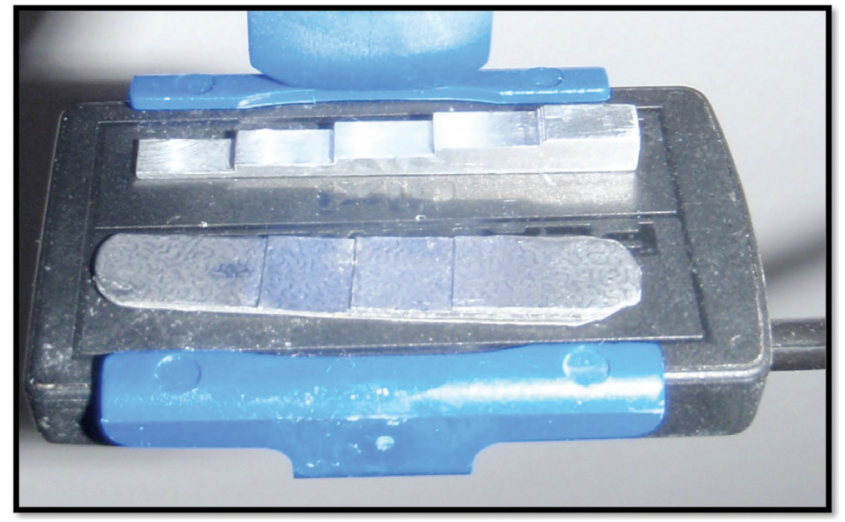

Fig. 1. The phantom consisting of 2 stepwages patterns placed on the receptor Dixi 3 (upper from aluminium, and bottom from lead)

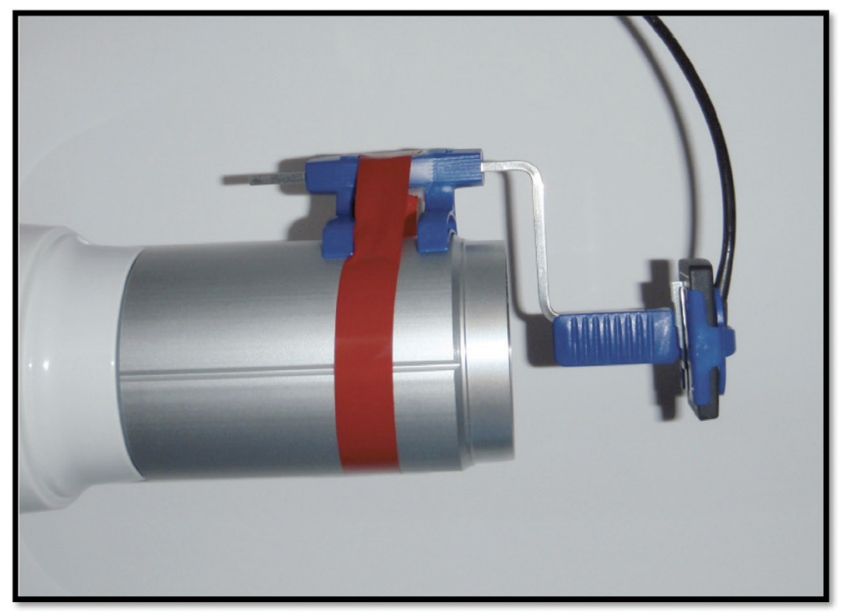

Fig. 2. The setting of the tube, the holder and the receptor during exposure

v. 4.2.0 (Planmeca). The Dimaxis Classic software was also used for image analysis export and import. The images were recorded after fastening the receptor and a holder to a 30-cm-long tube. The abovementioned patterns were located on the sensor surface (Fig. 2).

A distance of $4 \mathrm{~cm}$ between the tube of the Planmeca Intra and the Dixi 3 sensor was kept constant. Likewise, the position of the patterns on the surface of the sensor was constant. The selected parameters of the exposure were $60 \mathrm{kV}$ and $8 \mathrm{~mA}$, whereas the exposure time was the only variable.

A series of 7 images were recorded (256-grade 8-bit grayscale) with exposure times of $0.05 \mathrm{~s}, 0.064 \mathrm{~s}, 0.08 \mathrm{~s}$, $0.1 \mathrm{~s}, 0.125 \mathrm{~s}, 0.16 \mathrm{~s}$, and $0.2 \mathrm{~s}$, at the maximum resolution and equivalent software settings (Group A). Radiographs captured with exposure times of $0.05 \mathrm{~s}$ and $0.125 \mathrm{~s}$, without any manual image correction, were exported from the software using 2 different file export options. The $1^{\text {st }}$ one exported the image relying on default software settings with the automated picture adjustment algorithm turned on (the "export" function), whereas the $2^{\text {nd }}$ one exported "the clear" image without an automated picture 


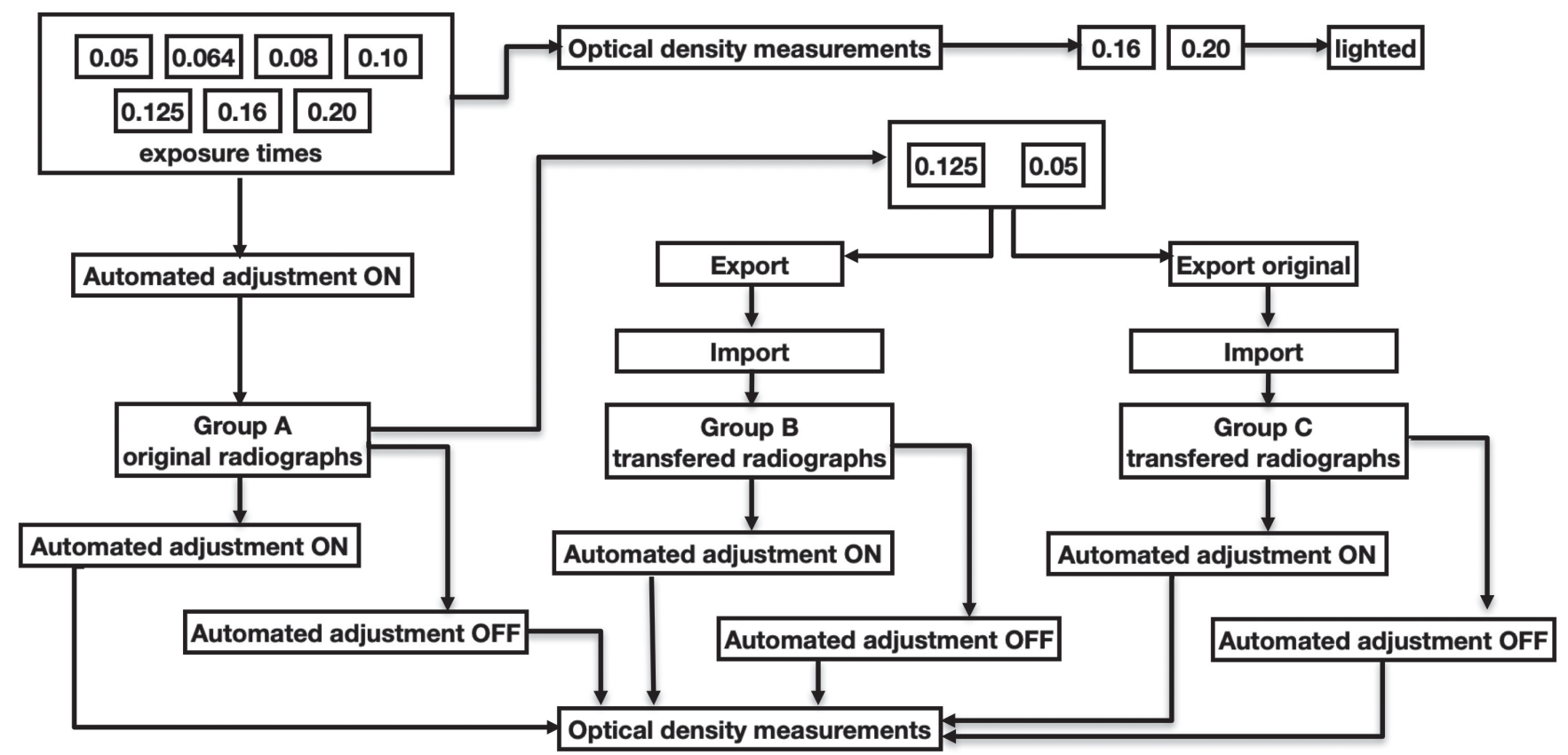

Fig. 3. Diagram of the procedures of export, import and optical density measurement during research

adjustment algorithm (the "original export" function). The exported files were saved in the lossless TIFF format. Then, the resulting radiograph files were imported into the Dimaxis software. In this way, 3 groups of radiographs were received. The $1^{\text {st }}$ group of radiographs (Group A) included those which were originally made and recorded in the database of the Dimaxis software, whereas the $2^{\text {nd }}$ one (Group B) comprised of radiographs imported after having been exported with optimization performed by the software (the "export" option); the $3^{\text {rd }}$ one (Group C) comprised of radiographs imported after having been exported without optimization performed by the software, which is called "original export". A diagram of the procedures of export, import and optical density measurements used in the study are presented in Fig. 3.

All radiographs were analyzed according to the same scheme, where the regions of interest (ROIs) were marked on the pattern-free background (marked as 0 ) and on particular steps of the $1^{\text {st }}$ and $2^{\text {nd }}$ patterns. The parts of the $1^{\text {st }}$ pattern (the aluminum one) were marked in steps $1-5$ and the parts of the $2^{\text {nd }}$ pattern (the lead one) in steps 6-9. Higher figures refer to a higher degree of radioabsorption. The optical density for each of the ROIs was expressed by the software as an average value, together with standard deviation (SD) (Fig. 4). The mean value and SD of each ROI (in a 256-grade scale of grayness from 0 to 255) were recorded. The blackened areas have low values, whereas the light ones have high values because they show high radioabsorption. The number of pixels in the ROIs ranged from 18,500 to 20,000 (the size differences between the ROIs did not exceed 1,500 ppx).

Additionally, to evaluate the effect that the changes in exposure time, the internal image adjusting algorithms, and the transfer of the image files had on the optical density of the bone structure, a series of dry human jaw bone radiographs were performed with the aluminum pattern as described above. The images were analyzed by $2 \mathrm{ob}-$ servers with general dental knowledge about X-ray image evaluation.

\section{Results}

According to the study design, the $1^{\text {st }}$ stage consisted in collecting values of optical density for all exposure times after image registration in the patients' charts and without the image corrections being subjected to analysis on the PC connected to the Dixi3 sensor (Group A). The values of optical density in Group A are presented in Table 1 and Fig. 5. The data (Group A) showed the influence of exposure time on optical density when the image optimization algorithm was active (default software setting). When the exposure times ranged from $0.05 \mathrm{~s}$ to $0.125 \mathrm{~s}$, the optical density values measured along all phantom steps decreased with an increase in exposure time. The largest optical density decrease was observed for step $1-31.7 \%$ (14.2 \pm 2.2 at 0.05 compared to $9.7 \pm 1.4$ at 0.125$)$ - and the smallest was for step 9: $0.8 \%$ ( $234.0 \pm 1.9$ at 0.05 compared to $232.1 \pm 1.2$ at 0.125$)$. At exposure times of $0.05-0.125 \mathrm{~s}$ and over the whole optical density range, the differences between the degrees of the pattern were sufficient, i.e., the images had sufficient contrast. The Group A radiographs of bone specimen captured with exposure times of $0.125 \mathrm{~s}$ and $0.2 \mathrm{~s}$ are presented in Fig. 6. The excessive exposure time caused image disturbances of the objects with an optical density of less than 50. On the images captured with an exposure 


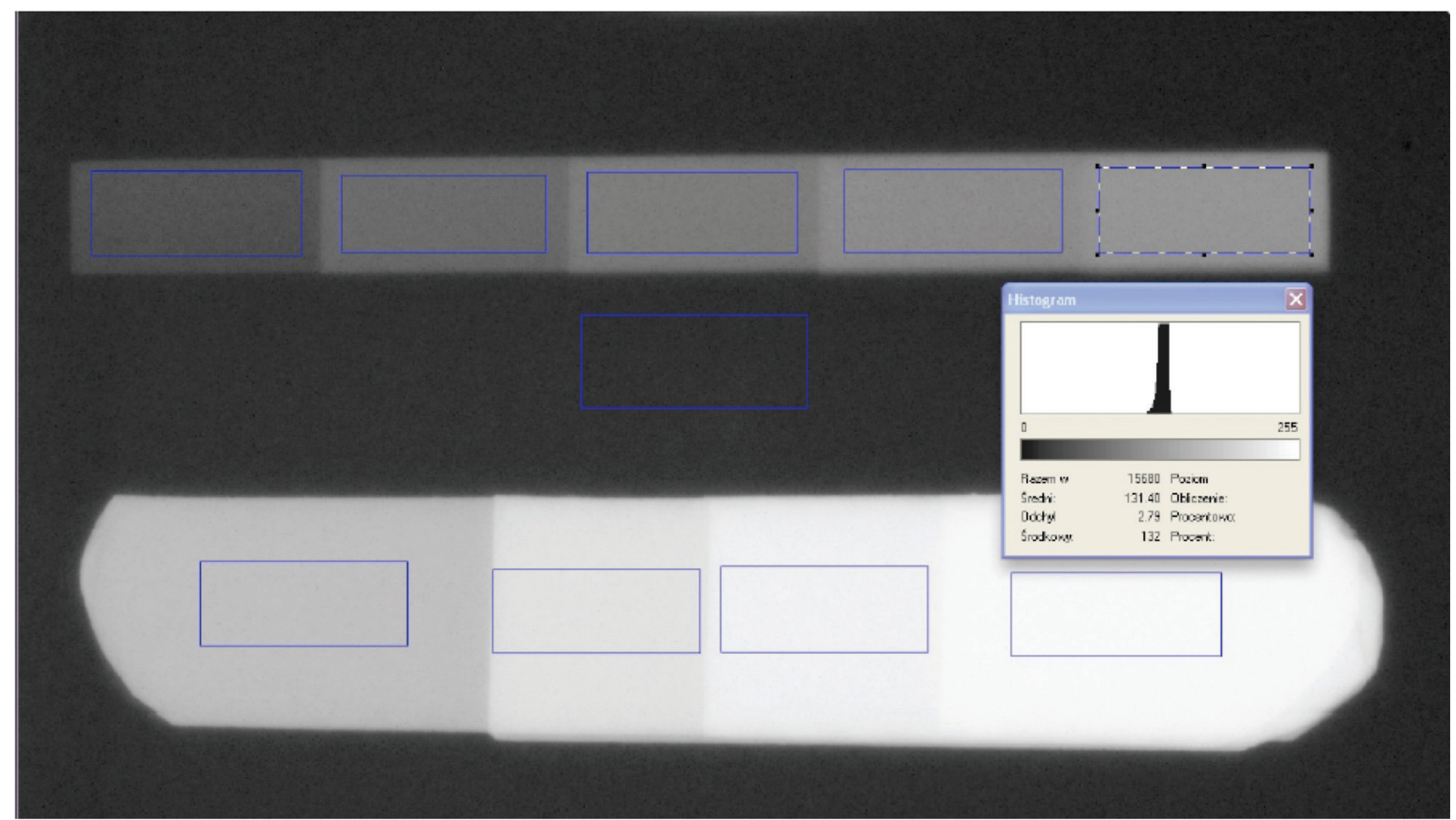

Fig. 4. The analyzed radiograph with the marked region of interest (ROI) and histogram of optical density

Table 1. The optical density values at different exposure times (Group A)

\begin{tabular}{|c|c|c|c|c|c|c|c|c|c|c|}
\hline \multirow{3}{*}{$\begin{array}{l}\text { Exposure } \\
\text { time } \\
{[s]}\end{array}$} & \multicolumn{10}{|c|}{ Degrees of the phantom } \\
\hline & 0 & 1 & 2 & 3 & 4 & 5 & 6 & 7 & 8 & 9 \\
\hline & $\mathrm{x} \pm \mathrm{SD}$ & $\mathrm{x} \pm \mathrm{SD}$ & $\mathrm{x} \pm \mathrm{SD}$ & $\mathrm{x} \pm \mathrm{SD}$ & $\mathrm{x} \pm \mathrm{SD}$ & $\mathrm{x} \pm \mathrm{SD}$ & $\mathrm{x} \pm \mathrm{SD}$ & $\mathrm{x} \pm \mathrm{SD}$ & $\mathrm{x} \pm \mathrm{SD}$ & $\mathrm{x} \pm \mathrm{SD}$ \\
\hline 0.05 & $3.5 \pm 1.1$ & $14.2 \pm 2.2$ & $28.7 \pm 2.8$ & $42.2 \pm 3.1$ & $57.9 \pm 3.4$ & $66.9 \pm 3.6$ & $127.6 \pm 3.5$ & $189.1 \pm 3.1$ & $218.7 \pm 2.3$ & $234.0 \pm 1.9$ \\
\hline 0.64 & $2.9 \pm 1.0$ & $13.0 \pm 2.0$ & $27.5 \pm 2.5$ & $40.7 \pm 2.8$ & $54.5 \pm 3.1$ & $65.4 \pm 3.3$ & $126.3 \pm 3.2$ & $188.6 \pm 2.7$ & $218.8 \pm 2.0$ & $234.4 \pm 1.6$ \\
\hline 0.80 & $2.0 \pm 0.8$ & $11.1 \pm 1.7$ & $24.8 \pm 2.1$ & $37.8 \pm 2.4$ & $51.3 \pm 2.8$ & $62.4 \pm 2.9$ & $122.8 \pm 2.8$ & $185.7 \pm 2.7$ & $216.4 \pm 1.8$ & $232.5 \pm 13$ \\
\hline 0.10 & $1.0 \pm 0.8$ & $11.1 \pm 1.7$ & $24.8 \pm 2.1$ & $37.8 \pm 2.4$ & $51.2 \pm 2.8$ & $62.3 \pm 2.9$ & $122.8 \pm 2.8$ & $185.7 \pm 2.4$ & $216.0 \pm 1.9$ & $232.4 \pm 1.4$ \\
\hline 0.125 & $3.2 \pm 0.5$ & $9.7 \pm 1.4$ & $22.8 \pm 2.0$ & $35.6 \pm 2.3$ & $49.0 \pm 2.4$ & $59.9 \pm 2.6$ & $120.9 \pm 2.4$ & $184.8 \pm 2.3$ & $215.9 \pm 1.6$ & $232.1 \pm 1.2$ \\
\hline 0.16 & $18.8 \pm 0.8$ & $18.9 \pm 0.9$ & $22.7 \pm 1.1$ & $33.0 \pm 2.0$ & $45.9 \pm 2.3$ & $56.6 \pm 2.6$ & $118.2 \pm 2.4$ & $183.1 \pm 2.3$ & $214.8 \pm 1.5$ & $231.1 \pm 1.2$ \\
\hline 0.20 & $45.0 \pm 1.2$ & $46.6 \pm 0.9$ & $47.4 \pm 0.8$ & $47.0 \pm 0.9$ & $48.0 \pm 1.6$ & $56.2 \pm 2.5$ & $118.0 \pm 2.3$ & $182.6 \pm 2.6$ & $214.8 \pm 1.5$ & $231.6 \pm 1.0$ \\
\hline
\end{tabular}

0 - the measurement area beyond the area of the density phantoms (the X-ray beam is directed to the receptor); SD - standard deviation.

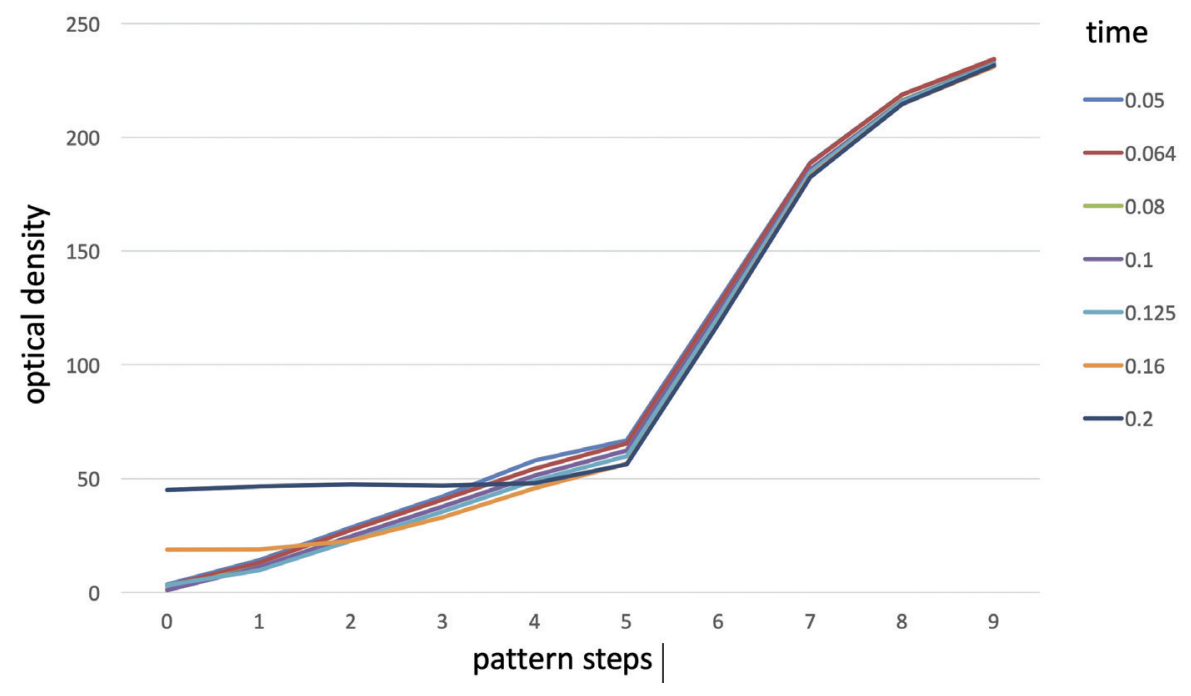

Fig. 5. The optical density values of Group A radiographs at different exposure times, automated adjustment turned on 


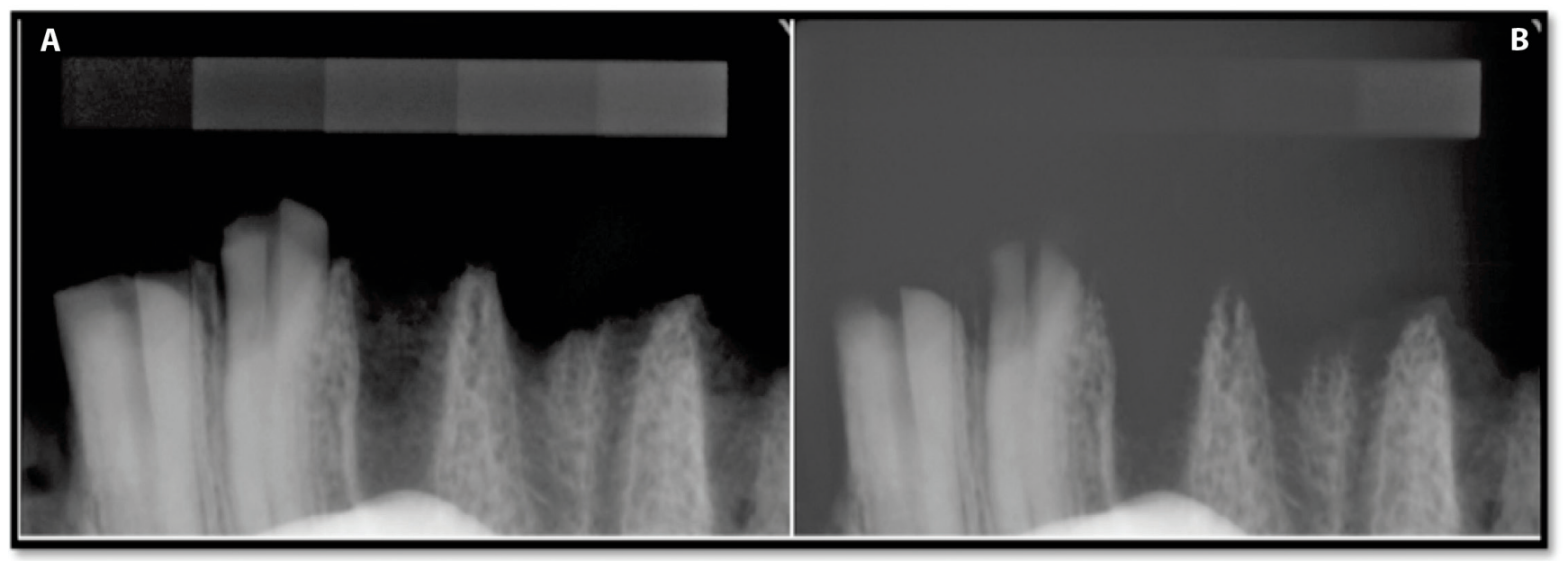

Fig. 6. Radiographs (Group A) performed at exposure time: A - 0.125 s; B - 0.2 s (overexposed)

Table 2. The optical density values at selected exposure times (Group A), with automated adjustment function on or off

\begin{tabular}{|c|c|c|c|c|c|c|c|c|c|c|c|}
\hline \multirow{3}{*}{$\begin{array}{c}\text { Exposure } \\
\text { time } \\
{[s]}\end{array}$} & \multirow{3}{*}{$\begin{array}{l}\text { Automated } \\
\text { adjustment }\end{array}$} & \multicolumn{10}{|c|}{ Degrees of the phantom } \\
\hline & & 0 & 1 & 2 & 3 & 4 & 5 & 6 & 7 & 8 & 9 \\
\hline & & $\mathrm{x} \pm \mathrm{SD}$ & $\mathrm{x} \pm \mathrm{SD}$ & $\mathrm{x} \pm \mathrm{SD}$ & $\mathrm{x} \pm \mathrm{SD}$ & $\mathrm{x} \pm \mathrm{SD}$ & $\mathrm{x} \pm \mathrm{SD}$ & $\mathrm{x} \pm \mathrm{SD}$ & $\mathrm{x} \pm \mathrm{SD}$ & $\mathrm{x} \pm \mathrm{SD}$ & $\mathrm{x} \pm \mathrm{SD}$ \\
\hline \multirow{3}{*}{0.05} & off & $45.6 \pm 4.5$ & $72.5 \pm 43$ & $96.0 \pm 3.9$ & $113.0 \pm 3.6$ & $127.5 \pm 3.5$ & $137.6 \pm 4.2$ & $184.9 \pm 2.3$ & $221.5 \pm 1.7$ & $237.1 \pm 1.2$ & $244.7 \pm 1.0$ \\
\hline & on & $3.5 \pm 1.1$ & $14.2 \pm 2.2$ & $28.7 \pm 2.8$ & $42.2 \pm 3.1$ & $57.9 \pm 3.4$ & $66.9 \pm 3.6$ & $127.6 \pm 3.5$ & $189.0 \pm 3.1$ & $218.7 \pm 2.3$ & $234.0 \pm 1.9$ \\
\hline & difference & $92.2 \%$ & $80.5 \%$ & $70.1 \%$ & $62.7 \%$ & $54.6 \%$ & $51.4 \%$ & $31.0 \%$ & $14.6 \%$ & $7.7 \%$ & $4.3 \%$ \\
\hline \multirow{3}{*}{0.125} & off & $37.4 \pm 1.7$ & $57.2 \pm 3.4$ & $82.3 \pm 3.2$ & $100.7 \pm 3.0$ & $116.5 \pm 2.7$ & $127.6 \pm 2.8$ & $178.1 \pm 1.9$ & $218.2 \pm 1.4$ & $235.2 \pm 1.0$ & $243.7 \pm 0.7$ \\
\hline & on & $3.2 \pm 0.5$ & $9.7 \pm 1.4$ & $22.8 \pm 2.0$ & $35.6 \pm 2.3$ & $49.0 \pm 2.4$ & $59.9 \pm 2.6$ & $120.9 \pm 2.4$ & $184.8 \pm 2.3$ & $215.9 \pm 1.6$ & $232.1 \pm 1.2$ \\
\hline & difference & $91.1 \%$ & $83.1 \%$ & $72.3 \%$ & $64.6 \%$ & $57.9 \%$ & $53.1 \%$ & $32.1 \%$ & $15.3 \%$ & $8.2 \%$ & $4.8 \%$ \\
\hline
\end{tabular}

0 - the measurement area beyond the area of the density phantom (X-ray beam is directed to the receptor); SD - standard deviation.

time of $0.16 \mathrm{~s}$, the differences between the background and steps 1 and 2 of the pattern were blurred and no considerable differences between these ROIs were noticed. With an exposure time of $0.2 \mathrm{~s}$, the differences were blurred not only between the background and steps 1 and 2, but also between the background and steps 3 and 4. Therefore, it can be stated that an object with low radioabsorption becomes imperceptible at exposure times of $0.16 \mathrm{~s}$ or $0.2 \mathrm{~s}$. A comparison of the bone specimen radiographs that were captured with exposure times of $0.125 \mathrm{~s}$ and $0.2 \mathrm{~s}$ displayed a blurred difference between the background and the object at a longer exposure time (Fig. 5).

The impact of the optimization algorithm on the Group A radiographs, which were captured at exposure times of $0.05 \mathrm{~s}$ and $0.125 \mathrm{~s}$, are presented in Table 2 and Fig. 7. The radiographs of the bone specimen captured with an exposure time of $0.125 \mathrm{~s}$ - with and without the automated adjustment option - are presented in Fig. 8.

The results demonstrate that the algorithm causes a reduction in the difference between particular exposure times as well as a reduction in optical density. The lower the optical density, the larger the decrease in optical density was recorded (Fig. 7). The decrease in optical density recorded for the exposure times of $0.05 \mathrm{~s}$ and $0.125 \mathrm{~s}$ at step 1 amounted to $80.5 \%$ and $83.1 \%$, respectively, and at step 9 it was $4.3 \%$ and $4.8 \%$, respectively. A detailed analysis of step 2 of the imaging phantom showed the difference between the optical density value for exposures of $0.05 \mathrm{~s}$ and $0.125 \mathrm{~s}$ to be 13.7 (96.0 \pm 3.9 compared to $82.3 \pm 3.2)$ with the automated adjustment function switched off, and only 5.9 (2.3 times lower) (28.7 \pm 2.8 compared to $22.8 \pm 2.0$ ) when the function was on. These changes can be seen in the radiographs of bone specimen (Fig. 7).

The use of automated adjustment resulted in the image becoming darker and more contrastive in areas with an optical density higher than 50 (phantom steps 5-9). The higher image contrast displaying the clearer structure of the object. However ROI's with low optical density became blurred (decrease of contrasts between steps 1 and 2, 2 and 3, 4 and 5) in comparison with the radiographs without the automated adjustment option. The algorithm made the $1^{\text {st }}$ degree of the pattern and a thin alveolar plate invisible to the observers (Fig. 7).

The optical density values of Group B and Group A images captured with exposure times of $0.05 \mathrm{~s}$ and $0.125 \mathrm{~s}$ are presented in Table 3 and Fig. 9. Radiographs of Group B with a bone specimen recorded with an exposure time of $0.125 \mathrm{~s}$ are presented in Fig. 10. The analysis of the Group B images transferred after exporting with 


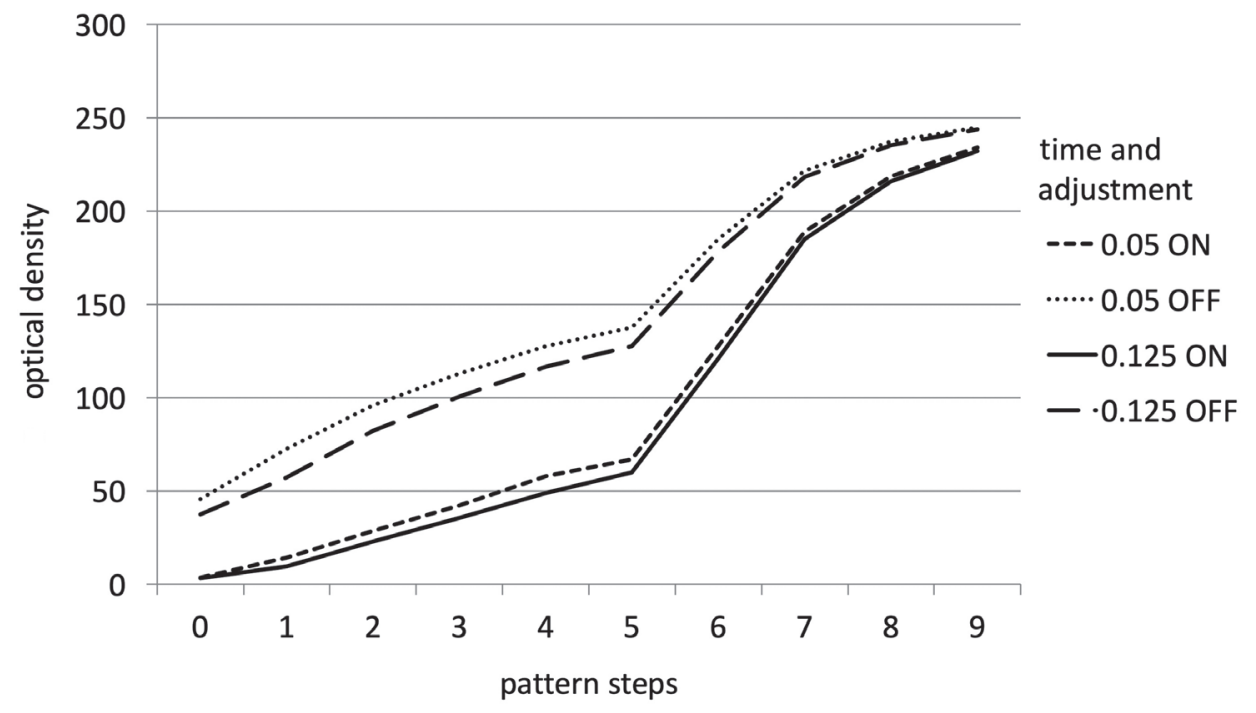

Fig. 7. The optical density values for the selected exposure times (Group A) automated adjustment turned on and of

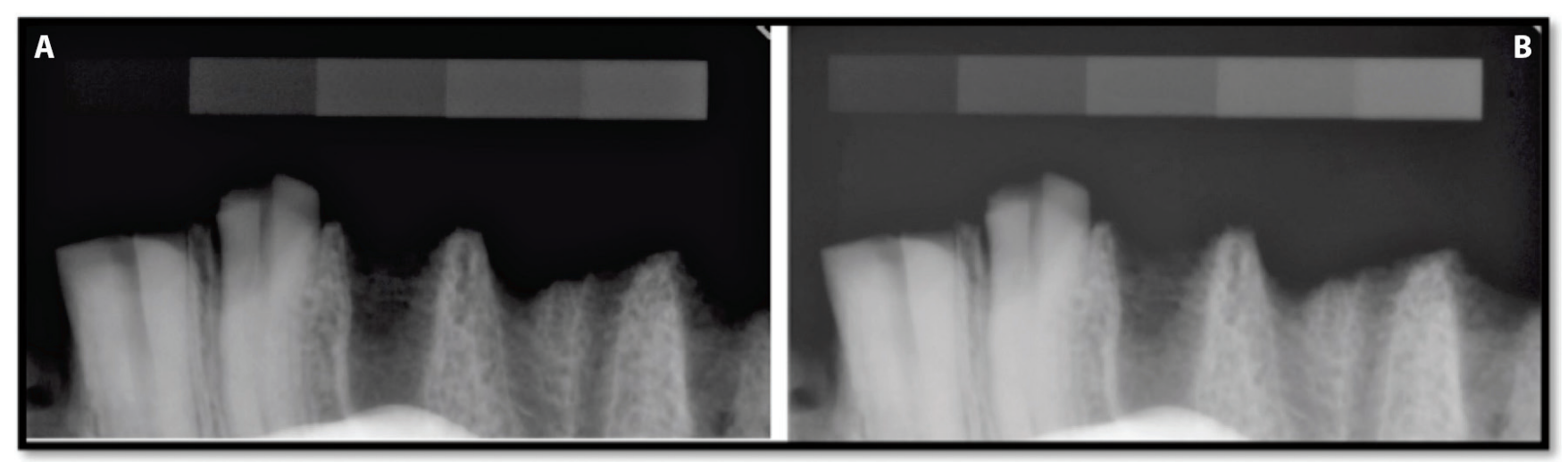

Fig. 8. Radiographs performed at exposure time $0.125 \mathrm{~s}$ (Group A), automated image adjustment: A - on; B - off.

Table 3. The optical density values after importing Group B files with selected exposure times, with automated adjustment function on or off

\begin{tabular}{|c|c|c|c|c|c|c|c|c|c|c|c|}
\hline \multirow{3}{*}{$\begin{array}{l}\text { Exposure } \\
\text { time } \\
{[s]}\end{array}$} & \multirow{3}{*}{$\begin{array}{l}\text { Automated } \\
\text { adjustment }\end{array}$} & \multicolumn{10}{|c|}{ Degrees of the phantom } \\
\hline & & 0 & 1 & 2 & 3 & 4 & 5 & 6 & 7 & 8 & 9 \\
\hline & & $\mathrm{x} \pm \mathrm{SD}$ & $\mathrm{x} \pm \mathrm{SD}$ & $\mathrm{x} \pm \mathrm{SD}$ & $\mathrm{x} \pm \mathrm{SD}$ & $\mathrm{x} \pm \mathrm{SD}$ & $\mathrm{x} \pm \mathrm{SD}$ & $\mathrm{x} \pm \mathrm{SD}$ & $\mathrm{x} \pm \mathrm{SD}$ & $\mathrm{x} \pm \mathrm{SD}$ & $\mathrm{x} \pm \mathrm{SD}$ \\
\hline \multirow{4}{*}{0.05} & on & 0 & $0.6 \pm 0.6$ & $3.4 \pm 1.2$ & $7.8 \pm 1.9$ & $13.9 \pm 2.6$ & $20.1 \pm 3.2$ & $73.2 \pm 6.4$ & $160.6 \pm 7.8$ & $214.2 \pm 7.2$ & $244.6 \pm 6.2$ \\
\hline & off & $3.7 \pm 1.8$ & $14.6 \pm 3.4$ & $29.1 \pm 4.4$ & $42.6 \pm 4.9$ & $56.2 \pm 5.7$ & $67.4 \pm 5.7$ & $128.3 \pm 5.7$ & $189.3 \pm 4.7$ & $219.0 \pm 3.7$ & $234.2 \pm 3.1$ \\
\hline & difference & $100 \%$ & $95.9 \%$ & $88.3 \%$ & $81.7 \%$ & $75.3 \%$ & $70.2 \%$ & $42.9 \%$ & $15.2 \%$ & $2.2 \%$ & $-4.4 \%$ \\
\hline & original & $3.5 \pm 1.1$ & $14.2 \pm 2.2$ & $28.7 \pm 2.8$ & $42.2 \pm 3.1$ & $57.9 \pm 3.4$ & $66.9 \pm 3.6$ & $127.6 \pm 3.5$ & $189.0 \pm 3.1$ & $218.7 \pm 2.3$ & $234.0 \pm 1.9$ \\
\hline \multirow{4}{*}{0.125} & on & 0 & $0.3 \pm 0.7$ & $2.3 \pm 1.1$ & $5.6 \pm 1.3$ & $10.9 \pm 1.8$ & $16.4 \pm 2.3$ & $67.7 \pm 4.8$ & $158.2 \pm 5.6$ & $215.7 \pm 5.0$ & $249.3 \pm 3.9$ \\
\hline & off & $3.3 \pm 0.7$ & $9.8 \pm 2.2$ & $22.9 \pm 3.1$ & $35.7 \pm 3.7$ & $48.9 \pm 4.1$ & $59.9 \pm 4.3$ & $121.4 \pm 4.3$ & $185.0 \pm 3.3$ & $216.0 \pm 2.5$ & $232.3 \pm 1.9$ \\
\hline & difference & $100 \%$ & $96.9 \%$ & $89.9 \%$ & $84.3 \%$ & $77.7 \%$ & $72.6 \%$ & $44.2 \%$ & $14.5 \%$ & $0.14 \%$ & $-7.3 \%$ \\
\hline & original & $3.2 \pm 0.5$ & $9.7 \pm 1.4$ & $22.8 \pm 2.0$ & $35.6 \pm 2.3$ & $49.0 \pm 2.4$ & $59.9 \pm 2.7$ & $120.9 \pm 2.4$ & $184.8 \pm 2.3$ & $215.9 \pm 1.6$ & $232.1 \pm 12$ \\
\hline
\end{tabular}

0 - the measurement area beyond the area of the density phantom (X-ray beam is directed to the receptor); original - with automated adjustment turned on (Group A); SD - standard deviation.

the "export" option (after optimization) revealed that after importing, some structures of the spongy bone (density equivalent to steps 1,2 and 3 of the phantom) may become undetectable. The use of automated adjustment, after file import, reduced the optical density values of the phantom radiographs from degree 1 to 8 , at exposure times of both $0.05 \mathrm{~s}$ (from $95.9 \%$ to $2.2 \%$ ) and $0.125 \mathrm{~s}$ (from 96.9\% to $0.14 \%$ ) - with the exception of degree 9 . The observed ROIs were black and steps 1 and 2 of the phantom also became invisible at shorter $(0.05 \mathrm{~s})$ and longer $(0.125 \mathrm{~s})$ exposure times. The image background achieves the optical density equal 0 and is totally black. The structures with higher radioabsorption remained visible and the optical density was reduced for steps 6 and 7 of the phantom. 


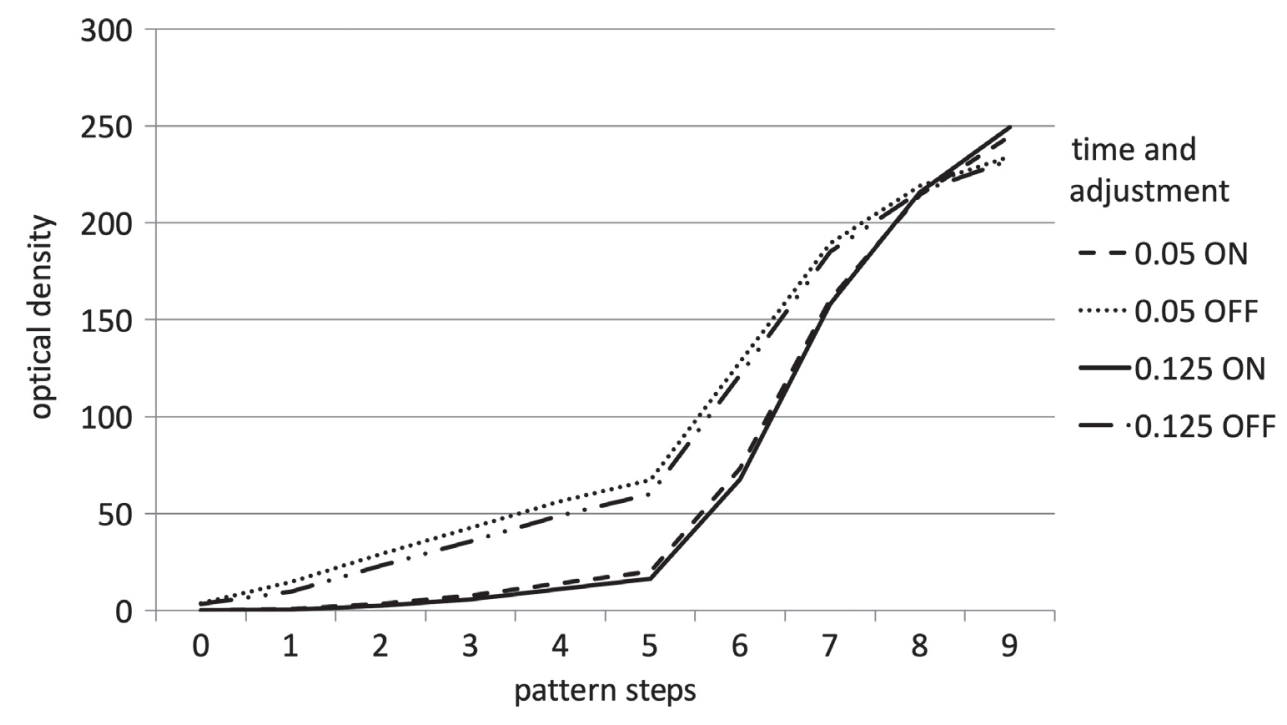

Fig. 9. The optical density values of Group B radiographs, exposure time 0.05 and $0.125 \mathrm{~s}$, automated adjustment turned on and off

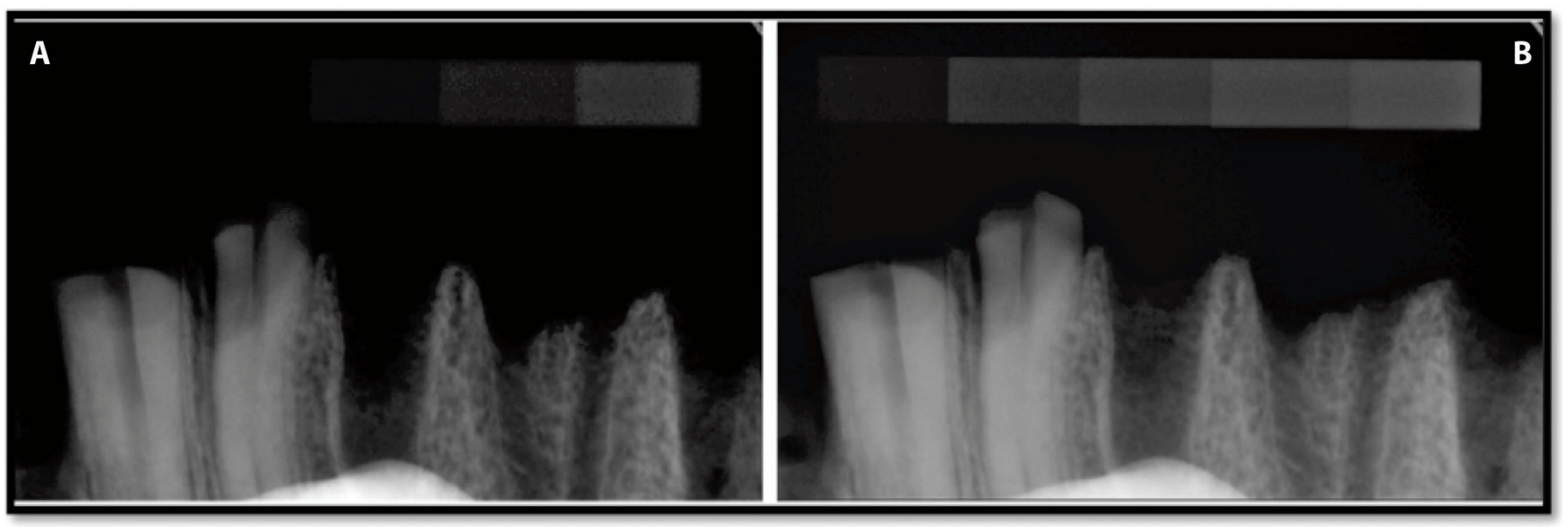

Fig. 10. Group B radiographs after import to Dimaxis software, automated image adjustment: A - on ("digital" underexposure) and B - off

It did not change in the case of step 8 and grew in the case of step 9 at both exposure times. The observed problems with the image were the result of using the optimization algorithm repeatedly. In this case, the algorithm should be turned off. Deactivating the optimization algorithm resulted in an optical density that was comparable (identical) with the original one at both exposure times and images that were less dark, displaying the object details more precisely (Fig. 9).

The recorded optical density values of the Group C radiograms captured at exposure times of $0.05 \mathrm{~s}$ and $0.125 \mathrm{~s}$ and the original images are presented in Table 4 and Fig. 11. The Group C radiograph of bone specimen captured at an exposure time of $0.125 \mathrm{~s}$ is presented in Fig. 12. The analysis of the Group C images (export without optimization) revealed that not applying the automated adjustment function after file import yielded an increase in the optical density values of the radiographs of all the phantom degrees over the original images (enhanced with the optimization algorithm). The increase was independent of exposure time (at $0.05 \mathrm{~s}$ the value changed from $80.2 \%$ to $4.4 \%$ and at 0.125 s from $82.9 \%$ to $4.7 \%$ ). However, activating this function (after import) provided an optical density almost identical to the original radiographs of all phantom degrees at both exposure times. Similarly Group C radiographs of the bone samples appears identical to those of Group A. (Fig. 7 and 11).

\section{Discussion}

Every image stored in the form of a file can be transferred, duplicated and changed digitally. Each adjustment which restores, improves, analyzes, or in some way changes a digital image is a form of image processing, e.g., image enhancement - brightness and contrast, sharpening and smoothening, or zooming in - or image analysis - measurement, segmentation, proportion finding, object classification, image synthesis, or compression.,

This type of processing does not alter the content of the image but does improve (or change) the visual perception to enable a better diagnosis., ${ }^{9,10}$ That is why understanding the individual of functions and their appropriate applications is extremely important in professional 
Table 4. The optical density values after importing Group C files with selected exposure times, with automated adjustment on or off

\begin{tabular}{|c|c|c|c|c|c|c|c|c|c|c|c|}
\hline \multirow{3}{*}{$\begin{array}{l}\text { Exposure } \\
\text { time } \\
{[\mathrm{s}]}\end{array}$} & \multirow{3}{*}{$\begin{array}{l}\text { Automated } \\
\text { adjustment }\end{array}$} & \multicolumn{10}{|c|}{ Degrees of the phantom } \\
\hline & & 0 & 1 & 2 & 3 & 4 & 5 & 6 & 7 & 8 & 9 \\
\hline & & $\mathrm{x} \pm \mathrm{SD}$ & $\mathrm{x} \pm \mathrm{SD}$ & $\mathrm{x} \pm \mathrm{SD}$ & $\mathrm{x} \pm \mathrm{SD}$ & $\mathrm{x} \pm \mathrm{SD}$ & $\mathrm{x} \pm \mathrm{SD}$ & $\mathrm{x} \pm \mathrm{SD}$ & $\mathrm{x} \pm \mathrm{SD}$ & $\mathrm{x} \pm \mathrm{SD}$ & $\mathrm{x} \pm \mathrm{SD}$ \\
\hline \multirow{4}{*}{0.05} & on & $3.5 \pm 1.1$ & $14.3 \pm 2.2$ & $29.0 \pm 2.8$ & $42.2 \pm 3.1$ & $55.9 \pm 3.3$ & $66.9 \pm 3.6$ & $127.9 \pm 3.5$ & $189.3 \pm 2.9$ & $218.7 \pm 2.3$ & $234.0 \pm 2.0$ \\
\hline & off & $44.8 \pm 4.4$ & $72.4 \pm 4.3$ & $96.0 \pm 3.9$ & $113.0 \pm 3.6$ & $127.6 \pm 3.4$ & $138.1 \pm 3.3$ & $184.8 \pm 2.4$ & $221.5 \pm 1.7$ & $237.0 \pm 1.2$ & $244.7 \pm 1.0$ \\
\hline & difference & $92.2 \%$ & $80.2 \%$ & $69.8 \%$ & $62.6 \%$ & $56.2 \%$ & $51.5 \%$ & $30.8 \%$ & $14.5 \%$ & $7.7 \%$ & $4.4 \%$ \\
\hline & original & $3.5 \pm 1.1$ & $14.2 \pm 2.2$ & $28.7 \pm 2.8$ & $42.2 \pm 3.1$ & $57.9 \pm 3.4$ & $67.0 \pm 3.6$ & $127.6 \pm 3.5$ & $189.1 \pm 3.1$ & $218.7 \pm 2.3$ & $234.0 \pm 1.9$ \\
\hline \multirow{4}{*}{0.125} & on & $3.2 \pm 0.5$ & $9.8 \pm 1.4$ & $22.7 \pm 2.0$ & $35.6 \pm 2.3$ & $48.9 \pm 2.5$ & $59.7 \pm 2.7$ & $120.8 \pm 2.6$ & $184.6 \pm 2.4$ & $215.7 \pm 1.6$ & $232.1 \pm 1.3$ \\
\hline & off & $37.3 \pm 1.7$ & $57.2 \pm 3.4$ & $82.3 \pm 3.2$ & $100.5 \pm 3.1$ & $116.2 \pm 2.8$ & $127.5 \pm 2.8$ & $178.3 \pm 1.9$ & $218.2 \pm 1.3$ & $235.3 \pm 0.9$ & $243.7 \pm 0.7$ \\
\hline & difference & $91.4 \%$ & $82.9 \%$ & $72.4 \%$ & $64.6 \%$ & $57.9 \%$ & $53.2 \%$ & $32.2 \%$ & $15.4 \%$ & $8.3 \%$ & $4.7 \%$ \\
\hline & original & $3.2 \pm 0.5$ & $9.7 \pm 1.4$ & $22.8 \pm 2.0$ & $35.6 \pm 2.3$ & $49.0 \pm 2.4$ & $59.9 \pm 2.6$ & $120.9 \pm 2.4$ & $184.7 \pm 2.3$ & $215.9 \pm 1.6$ & $232.1 \pm 1.2$ \\
\hline
\end{tabular}

0 - the measurement area beyond the area of the density patterns (X-ray beam is directed to the receptor); original - with automated adjustment turned on (Group A); SD - standard deviation.

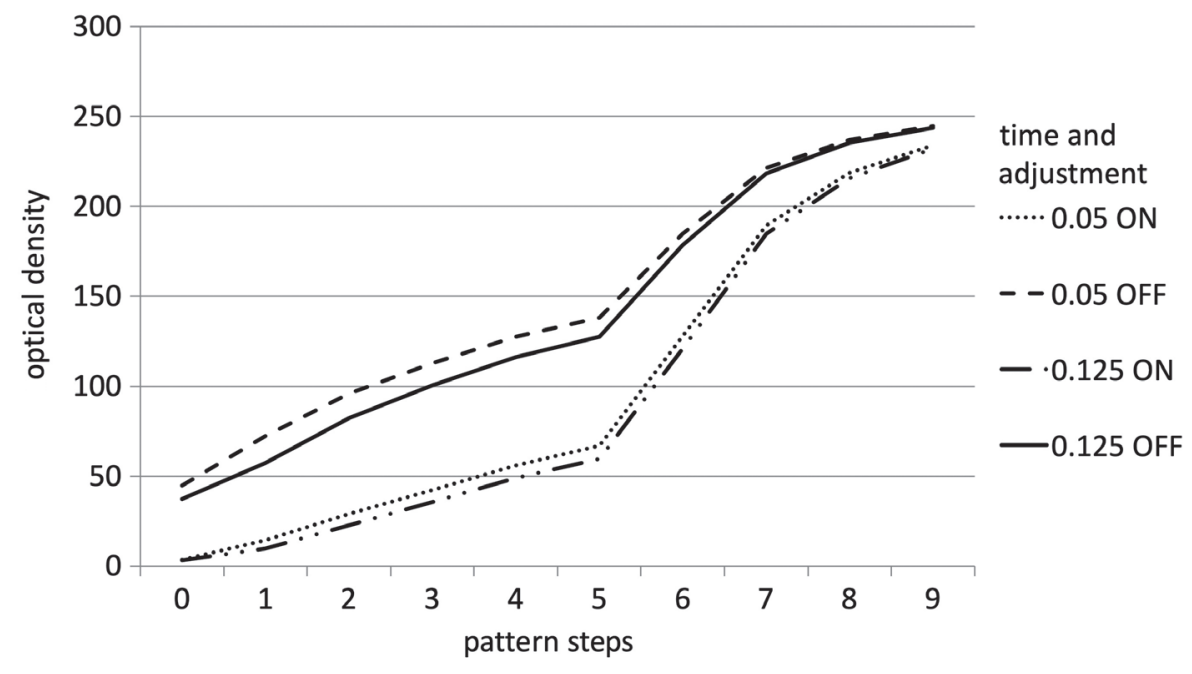

Fig. 11. The optical density values of Group C radiographs, exposure time 0.05 and $0.125 \mathrm{~s}$, automated adjustment turned on and off adjustment

$-\cdot 0.125 \mathrm{ON}$

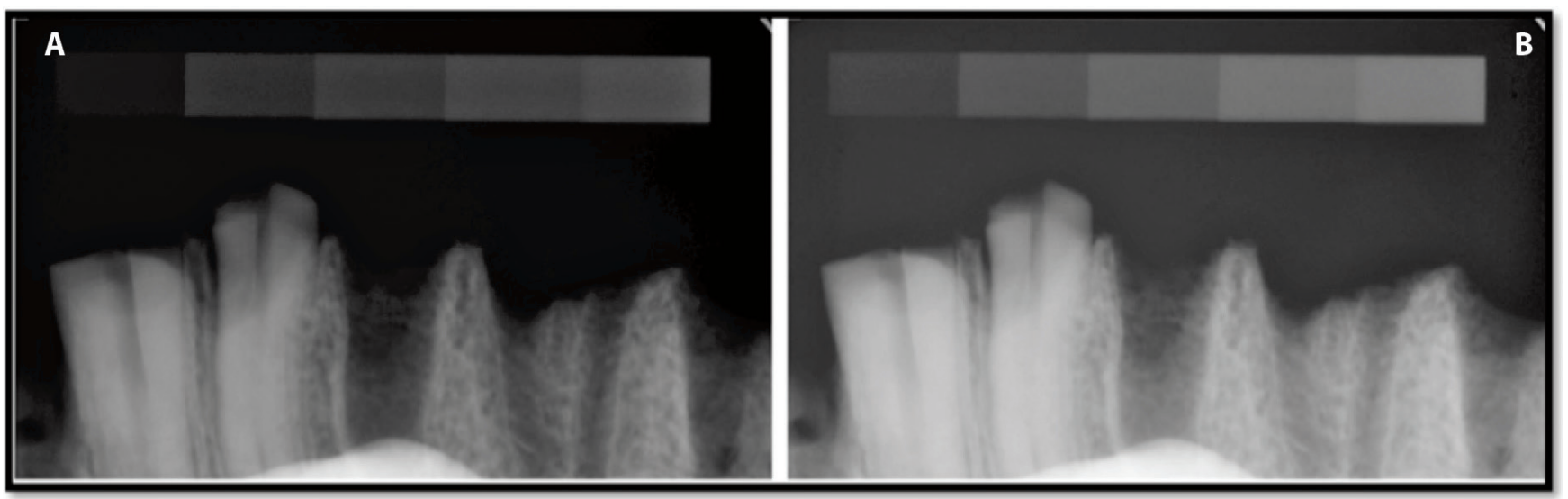

Fig. 12. Group C radiographs after import to Dimaxis software, automated image adjustment: A - on; B - off

work, regardless of the X-ray detector type. ${ }^{11}$ On the other hand, the exporting of digital radiographs to a file format that is compatible with commercial graphic software can cause some changes in the original digital information. ${ }^{4}$ For the purpose of this study, a simple pattern consisting of aluminum and lead steps with graded thicknesses were prepared. The use of the pattern allows exposure differences to be compensated for (and/or detected), the optical density to be calibrated, and finally, for different exposure conditions to be compared objectively. The use of an imaging phantom to measure bone optical density provides accurate and reproducible results and allows the impact of file transfers on qualitative and quantitative image changes to be measured. ${ }^{12}$ 
A similar device with fixed degrees of absorbed X-ray radiation was successfully used as a phantom by Yang et al. to measure the density of the jaw bone. ${ }^{13}$ The repeatability of projection and exposure is an important factor when digital images are compared. ${ }^{14,15}$ The use of a pattern simplifies the objective detection of and compensation for differences between objects with identical radioabsorption, as well as image calibration. On the other hand, the pattern covers a significant area of the small intraoral sensor or plate. Therefore, in clinical conditions, the use of a pattern is difficult or even impossible, especially when other structures overlap the image of the pattern. In most software used for dental radiography, instead of a phantom, some optimization algorithms are used to compensate for differences between the exposures. In clinical conditions, when it is difficult to maintain repeatability, the proper functioning of optimization algorithms is crucial.

The tools for measuring the optical density of bone radiographs and improving the image contrast are widely used during the evaluation of digital radiographs. Image manipulations, as well as the use of inappropriate monitors, affect perceptions; therefore, attention should be paid to the appropriate selection of exposure parameters and image correction tools. ${ }^{16}$ However, thoughtful and skillful application of these tools to detect root resorption can be applied according to the observer's preferences without affecting the diagnostic accuracy. ${ }^{17}$ The use of appropriate filters in digital radiology allows for a more accurate assessment of radiographs when dealing with inflammatory conditions of periapical tissues. ${ }^{18}$ Some filters, like the reverse of the grayscale, allows the image to be evaluated from a different aspect. However, it does not always have significant influence, e.g., in assessing the length of root canal instruments radiographically. ${ }^{19}$ Optical density measurement with the use of cone-beam computed tomography (CBCT) was also used to compare bone density around the impacted canines, which allowed a higher optical density of the bone surrounding the impacted teeth to be shown. ${ }^{20}$ The use of appropriate software may also help in the detection of general diseases such as osteoporosis based on dental X-ray radiographs. ${ }^{21,22}$ The correlation between the measurement of the bone density of alveolar bone and spinal bone indicates the importance of dentists being the first to pay attention to bone density disorders. ${ }^{23,24}$

When analyzing and comparing images, it should not be forgotten that the software usually compensates for variations in exposure parameters with automated optimizing algorithms. The option (algorithm) of automated adjustment, which corrects a digital image, is also included in the Dimaxis software that was used in this study. The default application of an optimization algorithm significantly reduces the differences between exposure times if they are in the range of $0.05-0.125 \mathrm{~s}$. The use of longer exposure times $(0.16 \mathrm{~s}$ and $0.2 \mathrm{~s})$ highlights the limitations of the software and the sensor used in this study, as it caused image disturbances of objects with an optical density of less than 50 . Because an object with low radioabsorption becomes imperceptible at exposure times of $0.16 \mathrm{~s}$ or $0.2 \mathrm{~s}$, those radiographs were recognized as "lighted." A similar selection was made in the article by Morea et al. due to the ghost images which were produced by an exposure time beyond the latitude of the sensor. ${ }^{16}$ Overexposure of the 0.16-second and 0.2-second images can also be caused by the lack of a soft-tissue-equivalent absorbing part of the radiation between the X-ray beam and sensor. The soft tissue model was not included in the current study. This assumption is confirmed in Fig. 7, where the operation of the algorithm is visible and makes the first-degree pattern and a thin alveolar plate invisible.

Suryani et al. presented the importance of post-processing the digital panoramic radiographs for a more accurate visualization of anatomical structures in children. ${ }^{9}$ Image quality processing techniques affect the quality of the image in various ways depending on the diagnostic purpose (caries, periapical lesion or root canal treatment) and must be properly selected. Based on the optical density of the ROIs, the use of automated image adjustment should be considered unfavorable because some structures may become invisible.

Bone density measurement to assess bone tissue and the images after importing is used in various studies. ${ }^{25}$ Measuring and comparing the density of selected jaw fragments is important when the healing or inflammation processes are compared over time. ${ }^{26}$ The efficacy of this method of testing the optical density of rat bones after the administration of ketoprofen was found by Martins et al. ${ }^{27}$ Disturbances in the readout of X-ray image parameters during transfer, such as optical density measurements or contrast differences, may be important in diagnosis. This was confirmed in studies in which the contrast change significantly changed the possibilities of measuring the length of small root canal instruments. ${ }^{28}$ However, accurate measurement of the optical density of bones is also important and may be a complement to $\mathrm{CT}$ analysis before implantation in the mandible. ${ }^{26}$ The results of the current study suggest that the automated adjustment function can disturb the process of image transfer (exporting from the raw data and importing to another database), and that in some cases, it can cause considerable differences in the recorded values of optical density. The analysis of Group B images revealed problems associated with the repeated use of image optimization, when areas with low radioabsorption become completely invisible. Importing files that have not been subjected to the optimization algorithm (Group C) seems to be safer, as there is no risk of image darkening or blurring of structures. In the era of digital radiology, the clinician assessing an imported radiograph should be aware of the possibility of such interference. In this study, a specific sensor and software were used, so the resulting limitations should be considered when analyzing the results. 


\section{Conclusions}

Within the limitations of this study, it can be concluded that 1) the transfer of digital radiographs can exert an influence on the recorded values of optical density, and thus on a comparative assessment, so the same (or a similar) algorithm of image processing should be used; 2) automated contrast enhancement and exposure compensation may blur the image of low-density structures; and 3) the radiogram files should be exported without image optimization. This way the risk of image distortion can be eliminated and the perception of low-density structures will not be distorted.

\section{ORCID iDs}

Wojciech Grzebieluch (10 https://orcid.org/0000-0003-0725-4620 Urszula Kaczmarek (1) https://orcid.org/0000-0002-9692-283X Tomasz Staniowski (D) https://orcid.org/0000-0001-5333-7289 Marcin Mikulewicz (D) https://orcid.org/0000-0001-5754-0284

\section{References}

1. Maschtakow PS,Moraes ME, Soares MG, Santos LR, Moraes LC, Castilho JC. Assessment of manipulation accuracy of digitized occlusal radiographic images-sub and over exposure. Acta Odontol Latinoam. 2009; 22(2):113-117.

2. Yoshiura K, Nakayama E, Shimizu M, et al. Effects of the automatic exposure compensation on the proximal caries diagnosis. Dentomaxillofac Radiol. 2005;34(3):140-144.

3. Brettle D, Carmichael F. The impact of digital image processing artefacts mimicking pathological features associated with restorations. BrDent J. 2011;211(4):167-170.

4. Calberson FL, Hommez GM, De Moor RJ. Fraudulent use of digital radiography: Methods to detect and protect digital radiographs. J Endod. 2008;34(5):530-536.

5. Gormez O, Yilmaz HH. Image post-processing in dental practice. Eur J Dent. 2009;3(4):343-347.

6. Shah N, Bansal N, Logani A. Recent advances in imaging technologies in dentistry. World J Radiol. 2014;6(10):794-807.

7. Piepenbring ME, Potter BJ, Weller N, Robert J, Loushine RJ. Measurement of endodontic file lengths: A density profile plot analysis. J Endod. 2000;26(10):615-618.

8. Butt A, Mahoney M, Savage NW. The impact of computer display performance on the quality of digital radiographs: A review. Aust Dent J. 2012;57(Suppl 1):16-23.

9. Suryani IR, Villegas NS, Shujaat S, et al. Image quality assessment of pre-processed and post-processed digital panoramic radiographs in paediatric patients with mixed dentition. Imaging Sci Dent. 2018; 48(4):261-268.

10. Svenson B, Larsson L, Båth M. Optimization of exposure in panoramic radiography while maintaining image quality using adaptive filtering. Acta Odontol Scand. 2016;74(3):229-235.

11. Farman AG, Farman TT. A comparison of 18 different detectors currently used in dentistry. Oral Surg Oral Med Oral Pathol Oral Radiol Endod. 2005;99(4):485-489.
12. Nackaerts $\mathrm{O}$, Jacobs $\mathrm{R}$, Horner $\mathrm{K}$, et al. Bone density measurements in intra-oral radiographs. Clin Oral Invest. 2007;11(3):225-229.

13. Yang J, Chiou R, Ruprecht A, Vicario J, MacPhail LA, Rams TE. A new device for measuring density of jaw bones. Dentomaxillofac Radiol. 2002;31(5):313-316.

14. Li G. Comparative investigation of subjective image quality of digital intraoral radiographs processed with 3 image-processing algorithms. Oral Surg Oral Med Oral Pathol Oral Radiol Endod. 2004;97(6):762-767.

15. Southard TE, Wunderle DM, Southhard KA, Jakobsen JR. Geometric and densitometric standardization of intraoral radiography through use of a modified XCP system. Oral Surg Oral Med Oral Pathol Oral Radiol Endod. 1999;87(2):253-257.

16. Morea C, Dominguez GC, Coutinho A, Chilvarquer I. Quantitative analysis of bone density in direct digital radiographs evaluated by means of computerized analysis of digital images. Dentomaxillofac Radiol. 2010;39(6):356-361.

17. Nascimento EHL, Gaêta-Araujo H, Galvão NS, Moreira-Souza L, OliveiraSantos C, Freitas DQ. Effect of brightness and contrast variation for detectability of root resorption lesions in digital intraoral radiographs. Clin Oral Investig. 2019;23(8):3379-3386.

18. Yalcinkaya S, Kunzel A, Willers R, Thoms M, Becker J. Subjective image quality of digitally filtered radiographs acquired by the Dürr Vistascan system compared with conventional radiographs. Oral Surg Oral Med Oral Pathol Oral Radiol Endod. 2006;101(5):643-651.

19. Oliveira ML, Vieira ML, Cruz AD, Bóscolo FN, de Almeida SM. Gray scale inversion in digital image for measurement of tooth length. Braz Dent J. 2012;23(6):703-706.

20. Servais JA, Gaalaas L, Lunos S, Beiraghi S, Larson BE, Leon-Salazar V. Alternative cone-beam computed tomography method for the analysis of bone density around impacted maxillary canines. Am J Orthod Dentofacial Orthop. 2018;154(3):442-449.

21. Lee JS, Adhikari S, Liu L, Jeong HG, Kim H, Yoon SJ. Osteoporosis detection in panoramic radiographs using a deep convolutional neural network-based computer-assisted diagnosis system: A preliminary study. Dentomaxillofac Radiol. 2018;48(1):20170344. doi:10.1259/ dmfr.20170344

22. Ayed MS, Shafiq SS, Diab HM, Alahmari AD, Divakar DD. Assessing periapical dental radiographs as a screening parameter for early indications of osteoporosis in postmenopausal periodontal patients and root surface evaluation using spectrochemical analysis. Saudi Med J. 2018;39(7):719-724.

23. Takaishi Y, Arita S, Honda M, et al. Assessment of alveolar bone mineral density as a predictor of lumbar fracture probability. Adv Ther. 2013;30(5):487-502.

24. Jin-Woo C, Won-Jeong H, Eun-Kyung K. Image enhancement of digital periapical radiographs according to diagnostic tasks. Imaging Sci Dent. 2014;44(1):31-35.

25. Kaczmarek U, Matthews-Brzozowska T, Mikulewicz M, Grzebieluch W. Evaluation of alveolar process bone density using digital radiography Digora: Experimental studies. Dent Med Probl. 2002;39:237-239.

26. Homolka P, Beer A, Birkfellner W, Gahnleitner A, Novotny R, Bergmann $\mathrm{H}$. Local calibrated bone mineral density in the mandible presented using a color coding scheme. Med Eng Phys. 2001;23(9): 673-677.

27. Martins MV, da Silva MA, Medici Filho E, de Moraes LC, Castilho JC, da Rocha RF. Evaluation of digital optical density of bone repair in rats medicated with ketoprofen. Braz Dent J. 2005;16(3):207-212.

28. Farhadi N, Shokraneh A, Mehdizadeh M. Effect of contrast inversion enhancement on the accuracy of endodontic file length determination in digital radiography. J Clin Diagn Res. 2015;9(5):ZC102-ZC105. 